\title{
Mask side-effects in long-term CPAP-patients impact adherence and sleepiness: the InterfaceVent real-life study
}

Marie-Caroline Rotty ${ }^{1,2}$, Carey M. Suehs ${ }^{3,4}$, Jean-Pierre Mallet ${ }^{2,3}$, Christian Martinez ${ }^{2}$, Jean-Christian Borel ${ }^{5}$, Claudio Rabec ${ }^{6}$, Fanny Bertelli ${ }^{1,2}$, Arnaud Bourdin ${ }^{2,3,7}$, Nicolas Molinari ${ }^{1,3}$ and Dany Jaffuel ${ }^{2,3,7,8^{*}}$ (D)

\begin{abstract}
Background: For some patients, Continuous Positive Airway Pressure (CPAP) remains an uncomfortable therapy despite the constant development of technological innovations. To date, no real life study has investigated the relationship between mask related side-effects (MRSEs) and CPAP-non-adherence (defined as $<4 \mathrm{~h} /$ day) or residualexcessive-sleepiness (RES, Epworth-Sleepiness-Scale (ESS) score $\geq 11$ ) in the long-term.
\end{abstract}

Methods: The InterfaceVent-CPAP study is a prospective real-life cross-sectional study conducted in an apneic adult cohort undergoing at least 3 months of CPAP with unrestricted mask-access (34 different masks). MRSEs were evaluated using visual-analogue-scales, CPAP-data using CPAP-software, sleepiness using ESS.

Results: 1484 patients were included in the analysis (72.2\% male, median age 67 years $\left(1 \mathrm{Q}_{25-75}: 60-74\right)$, initial ApneaHypopnea-Index (AHI) of $39(31-56) / \mathrm{h}$, residual AHI flow was $1.9(0.9-4)$ events/h), CPAP-treatment lasted 4.4 (2.0-9.7) years, CPAP-usage was $6.8(5.5-7.8) \mathrm{h} /$ day, the prevalence of CPAP-non-adherence was $8.6 \%$, and the prevalence of RES was $16.17 \%$. Leak-related side-effects were the most prevalent side-effects (patient-reported leaks concerned $75.4 \%$ of responders and had no correlation with (PAP-reported-leaks). Multivariable logistic regression analyses evaluating explanatory-variable (demographic data, device/mask data and MRSEs) effects on variables-of-interest (CPAP-non-adherence and RES), indicated for patient-MRSEs significant associations between: (i) CPAP-non-adherence and dry-mouth ( $p=0.004)$; (ii) RES and patient-reported leaks $(p=0.007)$, noisy mask $(p<0.001)$, dry nose $(p<0.001)$ and harness pain $(p=0.043)$.

Conclusion: In long-term CPAP-treated patients, leak-related side-effects remain the most prevalent side-effects, but patient-reported leaks cannot be predicted by CPAP-reported-leaks. Patient-MRSEs can be independently associated with CPAP-non-adherence and RES, thus implying a complementary role for MRSE questionnaires alongside CPAPdevice-reported-data for patient monitoring.

Trial registration InterfaceVent is registered with ClinicalTrials.gov (NCT03013283).

Keywords: Sleep apnea, Leaks, Side-effects, Telemedicine

${ }^{*}$ Correspondence: dany.jaffuel@wanadoo.fr

${ }^{2}$ Apard Groupe Adène, Montpellier, France

Full list of author information is available at the end of the article

\section{Background}

Sleep apnea syndrome (SAS) is a common sleep disorder with a prevalence ranging from $5.9 \%$ to $79.2 \%$ in European general populations over 35 years of age, depending on the clinical symptoms and apnea hypopnea scoring criteria used $[1,2]$. To date, despite major advances in

(c) The Author(s) 2021. This article is licensed under a Creative Commons Attribution 4.0 International License, which permits use, sharing, adaptation, distribution and reproduction in any medium or format, as long as you give appropriate credit to the original author(s) and the source, provide a link to the Creative Commons licence, and indicate if changes were made. The images or other third party material in this article are included in the article's Creative Commons licence, unless indicated otherwise in a credit line to the material. If material is not included in the article's Creative Commons licence and your intended use is not permitted by statutory regulation or exceeds the permitted use, you will need to obtain permission directly from the copyright holder. To view a copy of this licence, visit http://creativecommons.org/licenses/by/4.0/. The Creative Commons Public Domain Dedication waiver (http://creativecommons.org/publicdomain/zero/1.0/) applies to the data made available in this article, unless otherwise stated in a credit line to the data. 
alternative therapies, Continuous Positive Airway Pressure (CPAP) remains the cornerstone of SAS treatment $[3,4]$. Studies have shown that CPAP therapy can effectively reduce upper airway obstruction, with subsequent improvements in daytime sleepiness, sleep quality and quality-of-life, with all three of the latter being proportional to CPAP-usage $[5,6]$.

CPAP is an uncomfortable therapy for some patients. In large recent trials, CPAP-adherence (defined as a mean CPAP-usage for at least $4 \mathrm{~h}$ per day) can range from 53 to $92 \%$ at 6 months $[7,8]$. In observational studies, the frequency of initial refusal of CPAP varies from 5 to $50 \%$ of patients [9]. Factors that influence adherence to CPAP include disease and patient characteristics, psychological and social factors, follow-up techniques (linked to healthcare professionals and healthcare facilities), governmental policies, technological device factors and, particularly, mask related side-effects (MRSEs) [10, 11].

Despite the constant development of technological innovations for improving mask comfort (e.g., mask shape, different breathing routes, materials, ergonomic straps, rotating tube intersections, and lighter masks), the impact of such innovations is uncertain. In an observational study published in 1995, 50\% of the 193 patients complained of at least one MRSE [12]. Almost 20 years later, in the randomized controlled SAVE trial, $42 \%$ of patients complained of dry mouth [8]. In the latter study, the number of MRSEs (at 1 month) was an independent predictor of 12 month CPAP-adherence, thus confirming the relationship between the occurrence of short-term MRSEs and short-term CPAP-adherence. This relationship was confirmed in a 2311-patient real life cohort study, in addition to a significant relationship between CPAP-non-adherence and oronasal mask usage [13].

Similar data are lacking for long-term CPAP treated patients. Indeed, the 2019-published SAVE trial analysis [14] failed to demonstrate a relationship between MRSEnumber and 24-month CPAP-adherence. However, it is difficult to extrapolate the results of randomized studies to real life because of differences between real life and randomized studies in SAS symptoms, SAS severity and the care protocol proposed (mask and CPAP choices/ settings in particular). Unfortunately, other recent studies (randomized or real life) have not assessed the impact of MRSEs on long-term CPAP-adherence, nor on residual-excessive-sleepiness (RES, defined as an EpworthSleepiness-Scale (ESS) score $\geq 11$ ) [15-17]. For real life, long-term CPAP-treated patients, the hypothesis that mask related side-effects (MRSEs) may affect CPAPadherence or RES has never been investigated.

Therefore, the primary objective of the study reported herein is to describe MRSEs in a large population of SASpatients undergoing long-term CPAP therapy under real life conditions (including an unrestricted access to masks and CPAP-devices available on the market). The secondary objectives are to evaluate MRSE effects on CPAPadherence and RES.

\section{Methods \\ Study design and study population}

The InterfaceVent study (ClinicalTrials.gov: NCT03013283) is a prospective real-life cross-sectional study conducted from February 7, 2017 to April 1, 2019 in adults undergoing at least 3 months of CPAP or noninvasive ventilation. We herein report results for SASpatients treated exclusively by CPAP (see Fig. 1). SAS was defined according to the French Social Security (FSS) system criteria: (1) Apnea Hypopnea Index $(\mathrm{AHI}) \geq 30 / \mathrm{h}$ (or $\mathrm{AHI} \geq 15 / \mathrm{h}$ and more than $10 / \mathrm{h}$ respiratory-effortrelated arousal), and (2) associated with sleepiness and at least three symptoms from among snoring, headaches, hypertension, reduced vigilance, libido disorders, nocturia). The respect of these criteria is a stipulation for reimbursement by the FSS.

Following an initial prescription by one of the 336 device-prescribing physicians in the Occitanie region of France, these patients were provided care by the Apard ADENE group, a non-profit home care provider. Patient inclusion was performed during a scheduled home visit by one of the 32 Apard technicians (visits were scheduled according to the visits required for the reimbursement of the CPAP treatment by the FSS single payer system). No CPAP-adherence threshold was required for reimbursement and patients with poor compliance were not systematically excluded (see Additional file 1 for exclusion criteria).

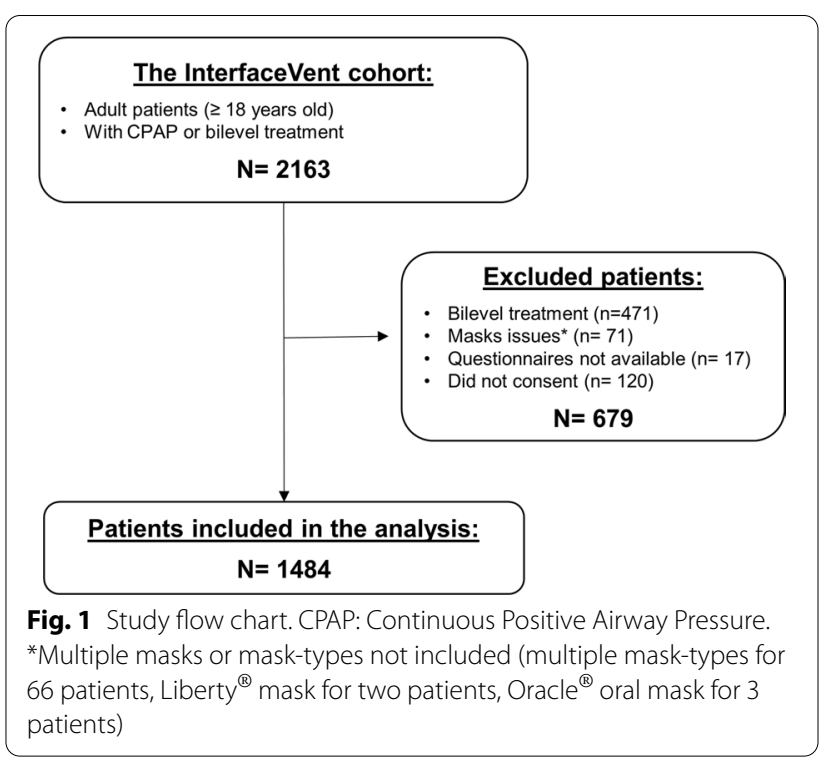




\section{Collected data}

Clinical information collected for the analysis is exhaustively summarized in the Additional file 1.

For patients with a CPAP-duration $>6$ months, data were collected only at the time of inclusion using CPAPsoftware and averaged over the last six months. For patients with 3-6 months CPAP, data were averaged for the last 3 months.

Side-effect visual analogue scales (VAS; see below), the Epworth-Sleepiness-Scale and the EQ-5D-3L questionnaire were administered during the scheduled visit by a technician employed by the home care provider. The technician did not help patients fill out the questionnaires. Residual Excessive Sleepiness (RES) was defined as an ESS score of $\geq 11$.

An 11-point VAS (0 (-no reported side-effect) to 10 (very uncomfortable side-effect) was used to assess the following MRSEs: dry mouth, partner disturbance due to leaks, patient-reported leaks, noisy mask, heavy mask, painful mask, mask injury, painful harness, harness injury, redness of the eyes, itchy eyes, dry nose, stuffed nose, and runny nose. The presence/absence of aerophagia and nose bleeding were also reported using a binary question.

Device-reported leak variables, as stipulated by each manufacturer, were included in the analysis. These differ according to each manufacturer's CPAP (see Additional file 2). For descriptive data, manufacturer-defined leak variables were used. For multivariable regression analyses, a pooled variable was used (see Additional files 3 and 4).

In order to compare masks on the basis of market availability, we divided them into two subgroups according to manufacturing date: those put on the market before 2013 (previous masks), versus those put on the market after 2013 (recent masks), see Additional file 5. This date was chosen based on the publication-year of the previous two large cohort studies evaluating the short-term impacts of MRSEs $[13,18]$.

\section{Statistical analyses}

Continuous data were expressed as medians with their associated quartile ranges due to non-Gaussian distributions. Qualitative parameters were expressed as numbers and percentages.

Mask-types were compared using ANOVA or Kruskal-Wallis tests for quantitative data, and Chisquare or Fisher tests for qualitative ones. For significant global comparisons, pairwise comparisons with Holm corrections were performed. Multivariable logistic or linear regression analyses were used to study associations between different variables-of-interest
(CPAP-non-adherence defined as a mean CPAP-usage for at least $4 \mathrm{~h}$ per day, Residual Excessive Sleepiness (RES, defined as an Epworth-Sleepiness-Scale (ESS) score $\geq 11$ ), patient-reported leaks) versus explanatoryvariables (demographic data, ESS score, EQ-5D-3L-questionnaires, device/mask data and MRSEs). Explanatory variables and multivariable regressions are exhaustively detailed in Additional files 6 and 7, respectively. To visualize correlations between MRSEs for a given mask type, a principal component analysis was performed for nasal, oronasal and nasal pillows masks [19, 20] (see Additional file 7). All statistical analyses were performed with SAS enterprise guide (V.7.1).

\section{Results}

The flow chart of the study is depicted in Fig. 1. Briefly, a total of 1484 patients were included $(72.2 \%$ male) in the analysis. The median age was $67\left(\mathrm{IQ}_{25-75}: 60-74\right)$ years; the median body mass index was $31(28-35) \mathrm{kg} / \mathrm{m}^{2}$; the median initial AHI was $39(31-56) / \mathrm{h}$, and $11.9 \%$ were active smokers. The median duration of the CPAP treatment was 4.4 (2.0-9.7) years; the median CPAP-usage was 6.8 (5.5-7.8) h/day; the CPAP-adherence was lower than $4 \mathrm{~h} /$ day for $8.6 \%$ of the patients and the median residual $\mathrm{AHI}_{\text {flow }}$ was $1.9(0.9-4)$ events/h. Overall, $28.4 \%$ of patients were treated with an oronasal mask (ONM), $54.4 \%$ with a nasal mask (NM), $17.2 \%$ with a nasal pillow mask (NPM), and $87.1 \%$ with auto-CPAP. The baseline characteristics of the population for each type of mask are summarized in Table 1. Additional file 8 shows the frequency distribution of the ESS scores in the whole population. The median ESS was 5 (3-9). The prevalence rate of RES (ESS score of $\geq 11$ ) was $16.17 \%$ of the whole population.

Additional file 5 summarizes the number of patients by brand, model and type of mask and Additional file 9 summarizes the brand, series and mode of CPAP devices. The prevalence of aerophagia and nose bleeding in our whole population were respectively $8.28 \%$ and $4.16 \%$, with no significant differences between mask-types (respectively $\mathrm{p}=0.47$ and $\mathrm{p}=0.75$ ).

\section{Prevalence of mask related side-effects}

MRSE frequencies (VAS score $\geq 1$ and VAS score $\geq 5$ ) are summarized in Table 2. Leak-related side-effects are the most prevalent type of side-effect. In particular, patientreported leaks concerned $75.4 \%$ of the respondents. There is no association between patient-reported and device-reported leaks (the Pearson correlation coefficient $r$ is only $0.007(\mathrm{p}=0.78)$, the regression coefficient is only $-0.0013(\mathrm{p}=0.79)$, see Fig. 2 and Additional file 10). Multivariable linear regression (Additional file 11) indicated that dry mouth, partner-disturbing leaks, noisy mask and 
Table 1 Population characteristics for each type of mask

\begin{tabular}{|c|c|c|c|c|c|}
\hline & $\begin{array}{l}\text { Whole Population } \\
(\mathrm{N}=1484)\end{array}$ & Nasal $(\mathrm{N}=807)$ & Oronasal $(\mathrm{N}=422)$ & Nasal Pillows $(\mathrm{N}=255)$ & p-value \\
\hline \multicolumn{6}{|l|}{ Demographics } \\
\hline Age (years) & $67[60 ; 74]$ & $67[61 ; 74]$ & $68[60 ; 74]$ & $66[59 ; 72]$ & 0.089 \\
\hline Gender, female (\%) & 27.8 & $30.2^{\mathrm{a}}$ & $21.3^{b}$ & $31.0^{\mathrm{a}}$ & 0.002 \\
\hline $\operatorname{BMI}\left(\mathrm{kg} / \mathrm{m}^{2}\right)$ & $31[28 ; 35]$ & $31[27 ; 35]$ & $31[28 ; 35]$ & $30[27 ; 35]$ & 0.31 \\
\hline Diagnostic AHI (events/h) & $39[31 ; 56]$ & $39[31 ; 55]$ & $39[31 ; 58]$ & $38[31 ; 52]$ & 0.86 \\
\hline Active smokers (\%) & 11.9 & 10.6 & 14.1 & 11.9 & 0.20 \\
\hline Beard (\%) & 17.0 & 17.3 & 17.4 & 15.1 & 0.22 \\
\hline Mustache (\%) & 10.4 & 8.5 & 13.4 & 10.8 & \\
\hline No mustache, no beard (\%) & 72.6 & 74.2 & 69.3 & 74.1 & \\
\hline Active workers (\%) & 20.6 & 19.3 & 20.5 & 24.8 & 0.18 \\
\hline Presence of partner (\%) & 72.2 & 71.2 & 73.1 & 73.9 & 0.64 \\
\hline \multicolumn{6}{|l|}{ Epworth Scale } \\
\hline ESS (0-24 score) & $5[3 ; 9]$ & $5[3 ; 8]$ & $6[3 ; 9]$ & $6[3 ; 9]$ & 0.16 \\
\hline RES (\%) & 16.2 & 15.1 & 17.1 & 18.0 & 0.46 \\
\hline \multicolumn{6}{|l|}{ EQ-5D-3L } \\
\hline Problems with mobility (\%) & 24.4 & $22.5^{\mathrm{a}}$ & $29.5^{b}$ & $21.9^{\mathrm{a}}$ & 0.017 \\
\hline Problems with self-care (\%) & 6.0 & 5.5 & 7.0 & 6.1 & 0.59 \\
\hline Problems with usual activities (\%) & 19.7 & 19.5 & 20.6 & 18.4 & 0.78 \\
\hline Problems of pain/discomfort (\%) & 58.4 & 56.4 & 61.2 & 58.8 & 0.25 \\
\hline Problems of anxiety/depression (\%) & 39.4 & $34.7^{\mathrm{a}}$ & $46.1^{b c}$ & $43.0^{c}$ & $<0.001$ \\
\hline EQ-5D-3L health VAS (0-100 score) & $70[50 ; 80]$ & $70[51 ; 80]^{\mathrm{a}}$ & $68[50 ; 80]^{b}$ & $70[51 ; 81]^{\text {ac }}$ & 0.006 \\
\hline \multicolumn{6}{|l|}{ Device } \\
\hline CPAP-usage (h/day) & $6.8[5.5 ; 7.8]$ & $6.8[5.6 ; 7.8]^{\mathrm{a}}$ & $6.5[5.3 ; 7.6]^{\mathrm{bc}}$ & $6.6[5.5 ; 7.6]^{c}$ & 0.022 \\
\hline Non-adherence (\%) & 8.6 & $6.3^{\mathrm{a}}$ & $11.6^{b}$ & $11.0^{\mathrm{b}}$ & 0.003 \\
\hline Current $\mathrm{AHI}_{\text {flow }}($ events/h) & $1.9[0.9 ; 4.0]$ & $1.7[0.9 ; 3.7]^{\mathrm{a}}$ & $2.7[1.3 ; 5]^{b}$ & $1.6[0.8 ; 3.0]^{\mathrm{ac}}$ & $<0.001$ \\
\hline Treatment duration (yrs) & $4.4[2.0 ; 9.7]$ & $4.4[1.6 ; 10.1]$ & $4.2[2.2 ; 9.3]$ & $5.1[2.4 ; 9.7]$ & 0.35 \\
\hline Mean Pressure $\left(\mathrm{cmH}_{2} \mathrm{O}\right)$ & $8.2[6.7 ; 10.0]$ & $8.0[6.4 ; 9.8]^{\mathrm{a}}$ & $9.1[7.6 ; 10.8]^{b}$ & $7.6[6.5 ; 9]^{a c}$ & $<0.001$ \\
\hline 90th/95th Pressure $\left(\mathrm{cmH}_{2} \mathrm{O}\right)$ & $10.0[8.1 ; 11.8]$ & $9.9[8.0 ; 11.4]^{\mathrm{a}}$ & $11.0[9.4 ; 12]^{\mathrm{b}}$ & $9.6[8 ; 11]^{\mathrm{ac}}$ & $<0.001$ \\
\hline Fixed pressure (\%), $n=1483$ & 12.9 & 13.0 & 12.8 & 12.9 & 0.99 \\
\hline Comfort mode (\%) & 15.8 & 16.2 & 14.7 & 16.1 & 0.77 \\
\hline Heated humidifier (\%) & 59.4 & $53.9^{\mathrm{a}}$ & $68.3^{b}$ & $62.0^{\mathrm{bc}}$ & $<0.001$ \\
\hline Heated breathing tube (\%) & 4.0 & 3.2 & 5.1 & 4.7 & 0.26 \\
\hline \multicolumn{6}{|l|}{ Mask } \\
\hline Mask availability since 2013 (\%) & 41.2 & $29.8^{\mathrm{a}}$ & $73.9^{\mathrm{b}}$ & $39.8^{c}$ & $<0.001$ \\
\hline Unintentional leaks (I/min) & $2.5[0 ; 7.5]$ & $2.5[0 ; 8.4]^{\mathrm{a}}$ & $1.2[0 ; 6]^{\mathrm{b}}$ & $1.5[0 ; 7]^{\mathrm{ab}}$ & $<0.001$ \\
\hline Unintentional large Leaks (\%) & $0.1[0 ; 0.9]$ & $0.1[0 ; 0.6]$ & $0.1[0 ; 2.5]$ & $0.1[0 ; 0.7]$ & 0.08 \\
\hline Global leaks (I/min) & $33[27 ; 41]$ & $31.5 ; 26 ; 37]^{\mathrm{a}}$ & $37(32 ; 49]^{b}$ & $32[26 ; 41]^{a b}$ & 0.014 \\
\hline Global large leaks (\%) & $0.9[0.1 ; 5.1]$ & $0.7[0.1 ; 3.1]$ & $2.7[0.2 ; 6.7]$ & $0.9[0.2 ; 5]$ & 0.11 \\
\hline Chin strap (\%) & 0.47 & 0.50 & 0.47 & 0.39 & 0.98 \\
\hline
\end{tabular}

AHI: Apnea-Hypopnea Index; $\mathrm{AHI}_{\text {flow }}$ : AHI reported by device; BMI: Body Mass Index; CPAP: Continuous Positive Airway Pressure; ESS: Epworth Sleepiness Scale; $\mathrm{N}=$ number of patients responding; Non adherence: CPAP-usage under $4 \mathrm{~h}$ per day; RES: Residual Excessive Sleepiness (ESS score > 10); VAS: Visual Analogue Scale. Leaks were obtained using CPAP built-in software (See Additional file 2: Table S1 for details). Data are reported as medians and quartiles or numbers and percentages of total as appropriate

Labels ${ }^{a}, \mathrm{~b}, \mathrm{c}$ : within a given line, mask-type subgroups with different letters are significantly different $(\mathrm{p}<0.05)$ according to post-hoc pairwise comparisons after Holm corrections. As an example, for the gender variable, there is a significant difference $(p=0.002)$ between mask-types. Post-hoc pairwise comparisons indicate that nasal-mask type is significantly different with oronasal-mask type (labels ${ }^{\mathrm{a}}$ and ${ }^{\mathrm{b}}$ are different), nasal pillows-mask type is also significantly different with oronasal-mask type (labels ${ }^{a}$ and $^{b}$ are different) but there is no significant different between nasal and nasal pillows-types (same label ${ }^{a}$ ) 
Table 2 Prevalence of mask related side-effects

\begin{tabular}{lll}
\hline Mask related side-effects & $\begin{array}{l}\text { \% of patients reporting VAS } \geq \mathbf{1} \text { (\% of population } \\
\text { responding positively to the question) }\end{array}$ & $\begin{array}{l}\text { \% of patients reporting VAS } \geq \mathbf{5} \text { (\% } \\
\text { of population responding positively } \\
\text { to the question) }\end{array}$ \\
\hline Patient-reported leaks (\%) & 75.4 & 39.5 \\
Dry mouth (\%) & 70.6 & 42.5 \\
Partner-disturbing leaks (\%) & 69.4 & 39.0 \\
Noisy mask (\%) & 57.5 & 22.6 \\
Dry nose (\%) & 54.4 & 25.6 \\
Stuffed nose (\%) & 41.7 & 17.6 \\
Red eyes (\%) & 36.2 & 14.7 \\
Itchy eyes (\%) & 36.0 & 13.1 \\
Runny nose (\%) & 36.0 & 14.0 \\
Heavy mask (\%) & 36.0 & 5.81 \\
Mask pain (\%) & 31.9 & 7.43 \\
Mask injury (\%) & 27.6 & 6.48 \\
Harness pain (\%) & 27.3 & 4.72 \\
Harness injury (\%) & 22.4 & 2.54 \\
\hline
\end{tabular}

VAS: Visual Analogue Scale

stuffed nose were all significantly associated with patientreported leaks regardless of the model considered (contrary to CPAP device-reported variables).

In the same patient, MRSEs can coexist. Additional file 12 summarizes the percentage of patients with 0 to 14 associated MRSEs. Principal Component Analysis (PCA) results (see Fig. 3, panel a) for NMs, panel b) for ONMs and panel c) for NPMs) suggest MRSE correlations that are homogenous across mask-types. However, Fig. 4 indicates additional mask differences in terms of specific VAS scores. For example, when comparing ONM to NM, higher MRSE VAS scores were found for patientreported leaks $(\mathrm{p}<0.001)$, partner-disturbing leaks $(\mathrm{p}<0.001)$, dry mouth $(\mathrm{p}<0.001)$, red eyes $(\mathrm{p}=0.005)$ and itchy eyes $(p=0.02)$. Similarly, when comparing ONM to NPM, higher MRSE VAS scores were found for patientreported leaks $(p=0.04)$, dry mouth $(p<0.001)$, red eyes $(p<0.001)$, and itchy eyes $(p=0.001)$. Finally, when comparing NPM to NM, higher MRSE VAS scores were found for partner-disturbing leaks $(p=0.013)$ only. In addition, the PCA suggests that the group of MRSE associated with mask complaints (PCA group-2) may be associated with the presence of a bed partner.

Additional file 13 depicts VAS for MRSE scores according to a bed partner presence or not. Noisy mask $(\mathrm{p}<0.001)$ and mask pain $(\mathrm{p}<0.05)$ are significantly associated with bed partner presence.

The MRSEs according to mask type and market availability are depicted in Additional file 14. Briefly, NMs available after 2013 provoke more red-eye symptoms than older masks. Recent ONMs are significantly more associated with partner-disturbing leaks and dry nose than older ones. Recent NPMs are also more associated with red eyes and itchy eyes than previous ones.

\section{Mask related side-effects, CPAP-non-adherence and residual-excessive-sleepiness}

The quasi-totality of patients $(1467 / 1478 ; 99.3 \%)$ position masks without assistance $(97.1 \%(1424 / 1466)$ easy to pose), $94.9 \%$ (1385/1460) were satisfied with their mask, 90.4 (1311/1451) of the patients considered masks as comfortable.

Table 4 summarizes the multivariable logistic regression analyses evaluating the impact of explanatory variables on CPAP-non-adherence and RES (see Table 3 for univariate analyses). In both models explaining CPAPnon-adherence, the latter was independently associated with lower age, lower $\mathrm{BMI}$, lower $\mathrm{p} 90 / 95^{\text {th }}$ pressure, availability of the mask since 2013, higher dry mouth and lower partner-disturbing leaks. Regardless of the model specification used, RES (Table 4) was independently associated with stronger anxiety/depression (estimated via the EQ-5D-3L anxiety/depression domain), lower quality-of-life (EQ-5D-3L-health VAS score), and higher VAS scores for noisy mask, patient-reported leaks, dry nose and harness pain.

\section{Discussion}

To our knowledge, this study is the first to report the prevalence of several MRSEs and their impact on CPAP-non-adherence and RES in a large cohort of long-term CPAP-treated patients. Patients were treated 


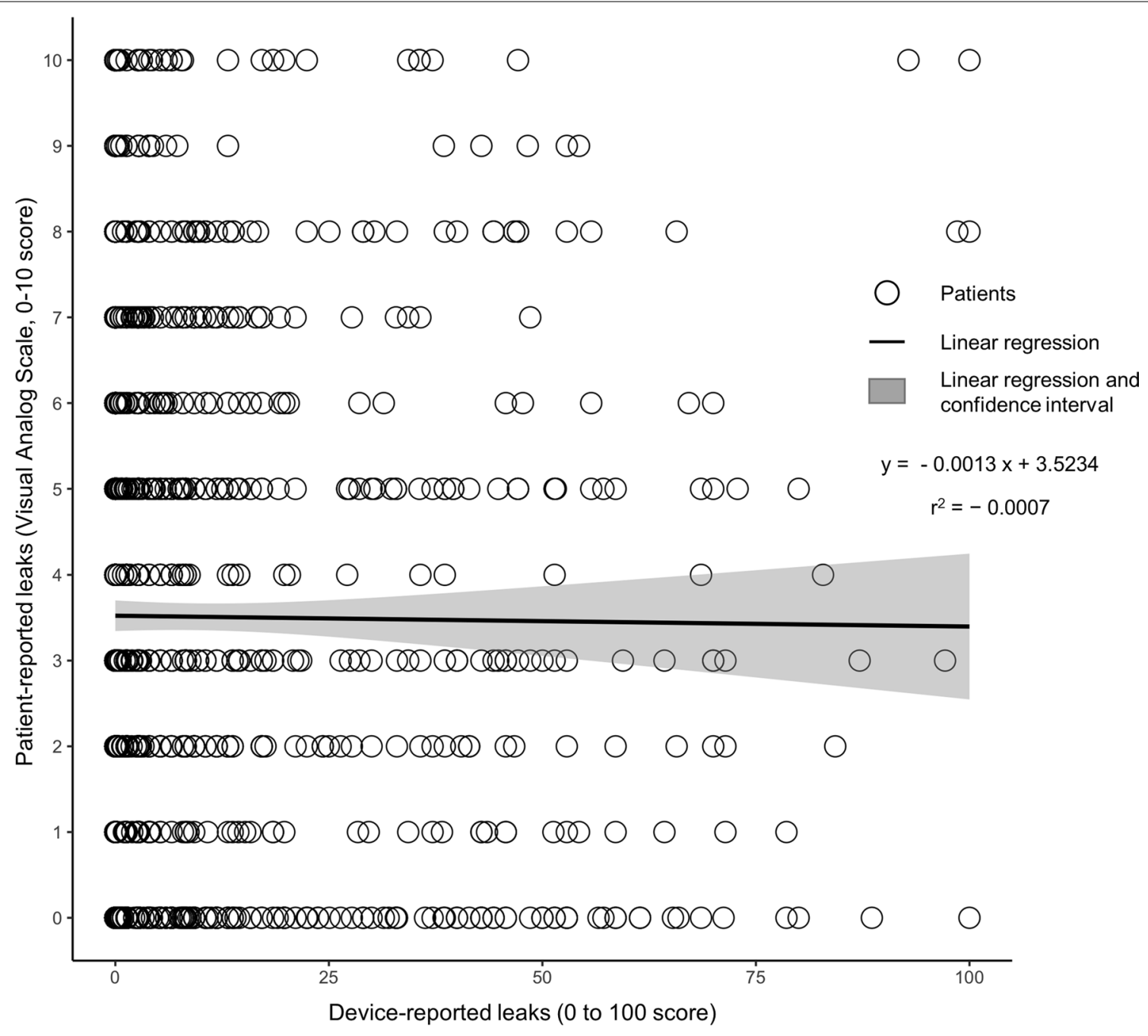

Fig. 2 Relationship between patient-reported leaks and device-reported leaks: individual data and linear regression

under real life conditions with an unrestricted access to masks and market-available CPAP devices. The main results reported here suggest that: (1) the most frequent side-effects in long-term CPAP-treated patients are patient-reported leaks, which are not predicted by CPAPdevice-reported data; (2) in long-term CPAP-treated patients, MRSEs are independently negatively associated with CPAP-adherence and positively associated with sleepiness, contrary to certain device-reported variables (CPAP-AHI $_{\text {flow }}$ and CPAP-reported leaks), which are not.

Prior to the availability of humidification systems, airway dryness was the most frequently reported side-effect (>50\% of CPAP-treated patients) [21]. In the 2000s, skin abrasions and mask leaks were considered as the most prevalent [22]. In 2013, two large cohorts reported MRSEs in short-term CPAP-treated patients [13, 18]. Additional file 15 summarizes the main data provided by these two studies; the most frequent side-effects were leak-related, as also found in the current study. In addition, we confirm that patient-reported leaks are not predicted by CPAP-reported leaks [18]. CPAP devices only record leak flows, whereas the patient's perception of a leak is a complex phenomenon involving not only the strength of the leak-flow itself but also how it feels on his/her skin/eyes (if the mask is not properly adjusted), and associated noises. In this regard, it is important to note that beards and moustaches were not associated with patient-reported leaks (as previously reported by Bachour et al. [18]).

Comparing the prevalence of MRSEs between studies is not simple. There are differences in the type of side-effects collected, as well as differences in the variables used (yes/no binary questionnaires, VAS and Likert scales). In addition, how patients perceive an MRSE is a complex phenomenon. Indeed, in the same study, the prevalence of MRSEs was reported to be different 

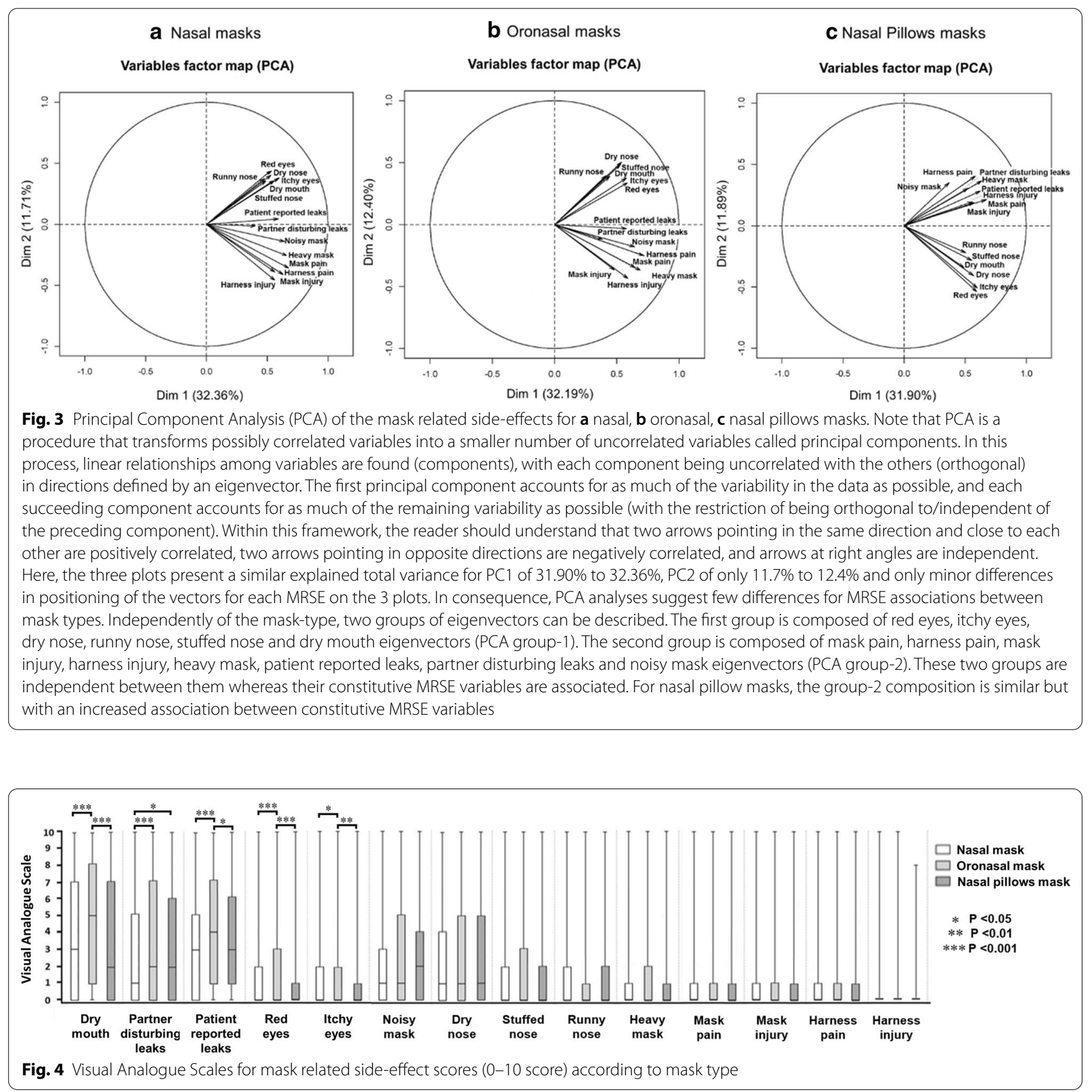

between a Caucasian population and an Asian population without a clear explanation why (cultural differences and/or reporting biases was preferentially suggested, rather than anatomical and/or physiological variations) [8]. Moreover, differences exist not only between masktypes, but also between brands or even series [18, 23]. There is a need for standardized questionnaires with a VAS or Likert scale rather than binary questions. Binary questions tend to censor positive responses from patients with less-severe complaints and thereby reduce the accuracy of statistical analyses. These limits were underlined in the 2019-American Academy of Sleep Medicine (2019-AASM) systematic review of CPAP-treatment for SAS patients [4].

Among the many factors that influence adherence of CPAP-treated patients, a good mask-type choice is of critical importance [24]. Two reviews and metaanalyses have reported a lower CPAP-adherence with ONMs compared with NMs, but they underlined that this difference was only observed in cohorts but not in 
Table 3 Univariate logistic analyses

\begin{tabular}{|c|c|c|c|c|}
\hline & \multicolumn{2}{|c|}{ CPAP-non-adherence ( $<4 \mathrm{~h} /$ day $)$} & \multicolumn{2}{|c|}{$\begin{array}{l}\text { Residual Excessive Sleepiness } \\
(\mathrm{ESS} \geq 11)\end{array}$} \\
\hline & Crude OR $[95 \% \mathrm{Cl}]$ & $P$ value & Crude OR $[95 \% \mathrm{Cl}]$ & $P$ value \\
\hline \multicolumn{5}{|l|}{ Demographics } \\
\hline Age (years) & $0.98[0.97 ; 1.00]$ & 0.046 & $0.99[0.97 ; 0.99]$ & 0.02 \\
\hline Gender, female & $0.55[0.34 ; 0.80]$ & 0.002 & $1.10[0.80 ; 1.50]$ & 0.55 \\
\hline $\mathrm{BMI}\left(\mathrm{kg} / \mathrm{m}^{2}\right)$ & $0.95[0.92 ; 0.99]$ & 0.012 & $0.99[0.96 ; 1.01]$ & 0.27 \\
\hline Diagnostic AHI (events/h) & $1.00[1.00 ; 1.00]$ & 0.25 & $0.99[0.99 ; 1.00]$ & 0.31 \\
\hline Active smokers & $1.40[0.84 ; 2.36]$ & 0.20 & $1.26[0.84 ; 1.89]$ & 0.27 \\
\hline Beard & $0.80[0.40 ; 1.60]$ & 0.31 & $1.34[0.88 ; 2.04]$ & 0.10 \\
\hline Mustache & $1.35[0.66 ; 2.74]$ & 0.27 & $0.80[0.44 ; 1.46]$ & 0.23 \\
\hline Active workers & $1.50[0.98 ; 2.29]$ & 0.059 & $1.36[0.98 ; 1.89]$ & 0.07 \\
\hline Presence of bed partner & $0.51[0.35 ; 0.74]$ & $<0.001$ & $0.93[0.69 ; 1.27]$ & 0.65 \\
\hline \multicolumn{5}{|l|}{ Epworth Scale } \\
\hline ESS (0-24 scores) & $1.00[0.99 ; 1.00]$ & 0.005 & NA & NA \\
\hline \multicolumn{5}{|l|}{ EQ-5D-3L } \\
\hline Problems with mobility & $1.18[0.78 ; 1.78]$ & 0.44 & $1.55[1.14 ; 2.11]$ & 0.005 \\
\hline Problems with self-care & $1.22[0.60 ; 2.51]$ & 0.58 & $1.50[0.89 ; 2.56]$ & 0.13 \\
\hline Problems with usual activities & $1.21[0.78 ; 1.89]$ & 0.39 & $2.06[1.50 ; 2.83]$ & $<0.001$ \\
\hline Problems of pain/discomfort & $1.10[0.76 ; 1.60]$ & 0.62 & $1.79[1.33 ; 2.42]$ & 0.001 \\
\hline Problems of anxiety/depression & $1.23[0.84 ; 1.78]$ & 0.29 & $2.42[1.82 ; 3.21]$ & $<0.001$ \\
\hline EQ-5D-3L health VAS (0-100 score) & $1.01[0.97 ; 1.01]$ & 0.071 & $0.99[0.99 ; 1.00]$ & $<0.001$ \\
\hline \multicolumn{5}{|l|}{ Device } \\
\hline CPAP-usage (h/day) & NA & NA & $0.99[0.99 ; 1.00]$ & 0.001 \\
\hline Current $\mathrm{AHI}_{\text {flow }}($ events/h) & $1.04[0.99 ; 1.09]$ & 0.054 & $0.99[0.95 ; 1.04]$ & 0.39 \\
\hline Treatment duration (years) & $0.93[0.89 ; 0.97]$ & $<0.001$ & $1.00[0.98 ; 1.03]$ & 0.93 \\
\hline Fixed pressure & $0.49[0.24 ; 0.98]$ & 0.043 & $0.67[0.43 ; 1.07]$ & 0.10 \\
\hline Mean pressure $\left(\mathrm{cmH}_{2} \mathrm{O}\right)$ & $0.92[0.84 ; 1.00]$ & 0.058 & $0.98[0.92 ; 1.05]$ & 0.68 \\
\hline 90th/95th pressure $\left(\mathrm{cmH}_{2} \mathrm{O}\right)$ & $0.93[0.85 ; 1.01]$ & 0.072 & $1.02[0.96 ; 1.09]$ & 0.43 \\
\hline Comfort mode & $1.33[0.84 ; 2.11]$ & 0.22 & $0.90[0.61 ; 1.32]$ & 0.58 \\
\hline Heated humidifier & $1.45[0.98 ; 2.12]$ & 0.061 & $1.12[0.84 ; 1.49]$ & 0.43 \\
\hline Heated breathing tube & $1.71[0.79 ; 3.68]$ & 0.17 & $1.06[0.53 ; 2.12]$ & 0.87 \\
\hline \multicolumn{5}{|l|}{ Mask } \\
\hline Nasal mask & Ref & 0.003 & Ref & 0.46 \\
\hline Oronasal mask & $1.95[1.29 ; 2.94]$ & 0.0625 & $1.16[0.84 ; 1.59]$ & 0.81 \\
\hline Nasal pillows mask & $1.83[1.13 ; 2.97]$ & 0.23 & $1.23[0.85 ; 1.79]$ & 0.44 \\
\hline Availability of the mask since 2013 (\%) & $2.49[1.72 ; 3.61]$ & $<0.001$ & $1.210 .92 ; 1.60]$ & 0.17 \\
\hline Device reported leaks (0-100 score) & $1.0[0.99 ; 1.02]$ & 0.23 & $1.00[0.99 ; 1.00]$ & 0.67 \\
\hline $\begin{array}{l}\text { Device reported leaks (median of the 95th percen- } \\
\text { tile of unintentional leaks }(1 / \mathrm{min}))\end{array}$ & $1.01[0.99 ; 1.02]$ & 0.34 & $0.99[0.98 ; 1.01]$ & 0.28 \\
\hline Chin strap & $1.00[1.00 ; 1.00]$ & 0.98 & $3.92[0.87 ; 17.6]$ & 0.07 \\
\hline \multicolumn{5}{|l|}{ Side effects } \\
\hline Dry mouth (0-10 VAS score) & $1.05[1.00 ; 1.11]$ & 0.044 & $1.14[1.09 ; 1.18]$ & $<0.001$ \\
\hline Partner disturbing leaks (0-10 VAS score) & $0.89[0.84 ; 0.95]$ & $<0.001$ & $1.08[1.05 ; 1.13]$ & $<0.001$ \\
\hline Patient reported leaks (0-10 VAS score) & $1.00[0.94 ; 1.06]$ & 0.96 & $1.15[1.10 ; 1.21]$ & $<0.001$ \\
\hline Red eyes (0-10 VAS score) & $1.01[0.94 ; 1.08]$ & 0.86 & $1.10[1.05 ; 1.15]$ & $<0.001$ \\
\hline Itchy eyes (0-10 VAS score) & $0.99[0.92 ; 1.07]$ & 0.90 & $1.11[1.05 ; 1.16]$ & $<0.001$ \\
\hline Noisy mask (0-10 VAS score) & $0.99[0.93 ; 1.07]$ & 0.90 & $1.16[1.10 ; 1.22]$ & $<0.001$ \\
\hline Dry nose (0-10 VAS score) & $1.04[0.99 ; 1.10]$ & 0.14 & $1.15[1.10 ; 1.20]$ & $<0.001$ \\
\hline Stuffed nose (0-10 VAS score) & $1.01[0.94 ; 1.08]$ & 0.81 & $1.13[1.09 ; 1.19]$ & $<0.001$ \\
\hline Runny nose (0-10 VAS score) & $0.97[0.90 ; 1.05]$ & 0.44 & $1.06[1.01 ; 1.12]$ & 0.013 \\
\hline
\end{tabular}




\begin{tabular}{|c|c|c|c|c|}
\hline & \multicolumn{2}{|c|}{ CPAP-non-adherence (< $4 \mathrm{~h} /$ day $)$} & \multicolumn{2}{|c|}{$\begin{array}{l}\text { Residual Excessive Sleepiness } \\
(E S S \geq 11)\end{array}$} \\
\hline & Crude OR $[95 \% \mathrm{Cl}]$ & $P$ value & Crude OR [95\% CI] & P value \\
\hline Heavy mask (0-10 VAS score) & $0.92[0.81 ; 1.04]$ & 0.18 & $1.20[1.12 ; 1.28]$ & $<0.001$ \\
\hline Mask pain (0-10 VAS score) & $1.05[0.96 ; 1.15]$ & 0.25 & $1.10[1.03 ; 1.20]$ & 0.003 \\
\hline Mask injury (0-10 VAS score) & $1.01[0.91 ; 1.11]$ & 0.90 & $1.11[1.04 ; 1.18]$ & 0.002 \\
\hline Harness pain (0-10 VAS score) & $1.07[0.96 ; 1.18]$ & 0.21 & $1.11[1.03 ; 1.20]$ & 0.006 \\
\hline Harness injury (0-10 VAS score) & $0.93[0.79 ; 1.09]$ & 0.36 & $1.12[1.03 ; 1.21]$ & 0.01 \\
\hline Nose bleeding & $0.53[0.17 ; 1.73]$ & 0.30 & $1.16[0.60 ; 2.27]$ & 0.66 \\
\hline Aerophagia & $1.45[0.80 ; 2.61]$ & 0.22 & $1.55[0.99 ; 2.44]$ & 0.056 \\
\hline Number* [0/14] & $1.01[0.96 ; 1.05]$ & 0.84 & $1.12[1.08 ; 1.16]$ & $<0.001$ \\
\hline
\end{tabular}

AHI: Apnea-Hypopnea Index, BMI: body mass index, CPAP: continuous positive airway pressure, ESS: Epworth Sleepiness Scale, OR: odds ratio; NA: not applicable, VAS: Visual Analogue Scale

Italics variables are included in multivariable analyses

* Number of side effects; dichotomous data created when the VAS scale for the side effect was above or equal to 1 . This variable was not included in the multivariable analyses because of its collinearity with MRSE-variables

randomized studies [4, 25]. Considering that MRSEs are different between mask-types [4], one hypothesis that likely explains differences between mask-types on CPAP-adherence might be that such differences are more the result of MRSEs than the mask-type per se. In this regard, at the multivariable level of analysis (model 1), we report that dry-mouth is associated with poor CPAPnon-adherence $(<4 \mathrm{~h} /$ day $)$, whereas the mask-type was not. Of course, it was impossible for us to rule out the possibility that a certain collinearity between MRSEs and mask type limits the statistical analysis. Previous studies reporting on how MRSEs impact CPAP-adherence concern only NM [26] or do not include mask-type as a variable of study [8,27]. Only Borel et al. included both MRSEs and mask-type in a multivariable analysis and found that ONM versus NM effects associated with CPAP-adherence, while dry mouth and nasal congestion became insignificant at the multivariable level [13]. The observed discrepancies between the present study and that by Borel et al. [13] can be explained by differences in study design, such as long versus short-term timeframes (fewer stable patients and fewer attempts at using different masks), or by the use of quantitative VAS scores versus a binary questionnaire that likely censors information.

We reported that the patients with an ONM or a NPM have a higher CPAP non-adherence than the patients with a NM. Similar results were observed in both a cohort study by Borel et al. [13] and in a 4-week randomized cross-over study by Goh et al. [28]. On the contrary, Rowland et al. found no significant difference between the mask-types on CPAP non-adherence when comparing $\mathrm{NM}$ and ONM in a 4-week randomized cross over trial [29]. To explain certain similarities and discrepancies between these studies and ours, it is important to keep in mind that: (i) in accordance with the 2010 French national recommendations, the mask-type national policy was to use a NM as the first intention mask in newly CPAP-treated patients [30]; (ii) in our study, the patients had access to 34 different masks and were treated on a long-term basis (median CPAP-treatment duration of 4.4 $\left[\mathrm{IQ}_{25 ; 75}: 2.0 ; 9.7\right]$ years, with an unrestricted mask-type use and potentially several mask-type sequences before inclusion). So we cannot rule out that our reported CPAP non-adherence might be impacted by this initial choice of a NM and/or the different mask-type sequences. For most patients, NPM and ONM choices were probably an alternative/catch-up choice because of a NM problem, rather than a first choice.

We also included CPAP-reported variables in our multivariable regression models. Our study confirms that higher levels of CPAP-pressure are predictive of higher compliance $[13,14,31,32]$, but neither $\mathrm{AHI}_{\text {flow }}$ nor device-reported leaks were significantly associated with CPAP-non-adherence in these long-term CPAP-treated patients. However, dry mouth is. Furthermore, we report ESS scores to be significantly associated with MRSEs whereas $\mathrm{AHI}_{\text {flow }}$ and device-reported leaks are not. Altogether, these results suggest that MRSE questionnaires should be included with CPAP-reported data during patient follow-up and particularly in long-term tele-monitoring programs [33].

We reported that the CPAP-mode (fixed versus autoadjusting pressure) has no impact on CPAP-non adherence nor on RES. These data are in accordance not only with the results of a recent meta-analysis of two randomized clinical trials on CPAP-non adherence, but also with 19 studies on ESS [4]. 


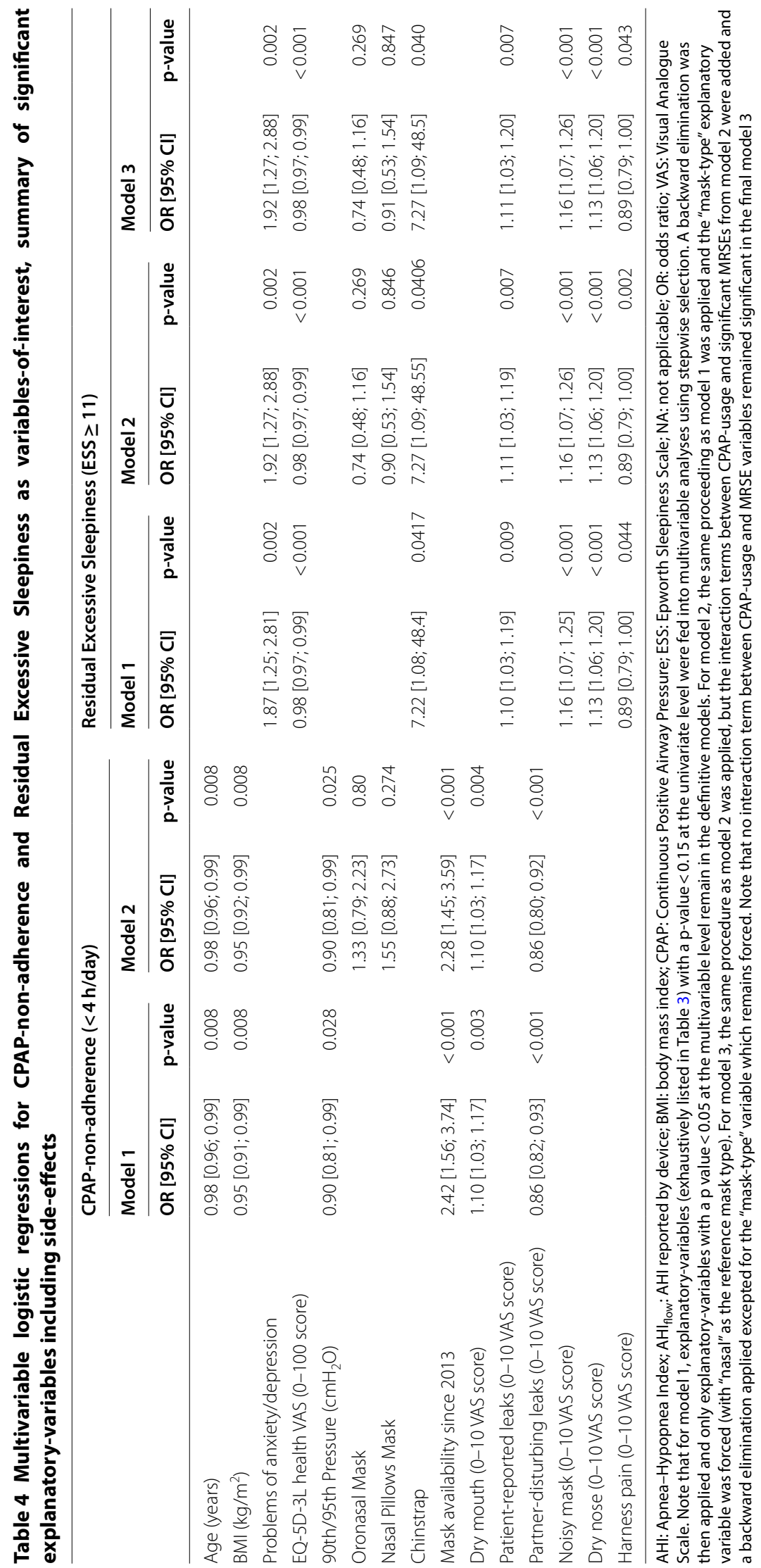




\section{Study limitations}

One part of our results can be explained by an inherent bias in the real-life design of our study. We not only report that "mask availability since 2013" is associated with CPAP-non-adherence $(<4 \mathrm{~h} /$ day $)$, but also that MRSEs are more prevalent with recent. This finding could be partly explained by the fact that patients with previous/prominent MRSEs may have been more likely to have changed/upgraded masks and thus have a newer one at the time of the study. Another explanation could be that very long-term treated patients were historically treated with "older-masks". During planned technician visits, these patients may also have tried "recent-masks", whereas for newer patients, only the more "recentmasks" are proposed in order to limit the risk of rapid obsolescence. Bachour et al. reported that $20 \%$ of patients were unsatisfied with their newer mask when a systematic switch was necessary because of obsolescence [23]. Thus, only mask-incident patients and a randomized trial design would resolve questions concerning the benefits of old-versus-new masks. It is also important to underline that newer mask-types such as nasal cradles or minimal contact nasal/oronasal mask-types were very rarely or not used in our study, so our findings do not apply to these newer mask-types.

That $95 \%$ and $90 \%$ of patients were satisfied with their mask or considered it comfortable (respectively), whereas $>75 \%$ reported $\geq 1$ MRSE, presents a paradox. We believe this is a consequence of (i) the 11-point MRSE VAS used in our study (for most patients, a MRSE exists but is not considered "uncomfortable or very uncomfortable"); (ii) patients are long-term treated ( $>75 \%$ of patients are treated $\geq 2$ years). Therefore, we cannot rule out that our population preferentially included the most MRSE tolerant patients with high levels of CPAP-usage.

The long-term design of our study is both a strength (that sets it apart from previous studies) and a limitation. Patients may have been treated with several masks and mask-types before inclusion and we cannot determine if the prevalence/severity of MRSEs were impacted by different mask sequences. Finally, our conclusions may not be applicable to short-term situations ( $<3$ months) or a younger/older patient population than that included in our study.

\section{Conclusions}

In long-term CPAP-treated patients, patient-reported leaks are counter-intuitively not associated with devicereported leaks, and remain the most prevalent side effect. Additionally, MRSEs are associated with CPAP-nonadherence and RES. Considering the future care of millions of patients on a long-term basis, our study suggests a complementary role for MRSE-questionnaires and CPAP-reported data during telemedicine $[34,35]$.

\section{Supplementary Information}

The online version contains supplementary material available at https://doi. org/10.1186/s12931-021-01618-x.

Additional file 1. Methods.

Additional file 2. Information (leaks and pressures) obtained by downloading device data according to manufacturer and device.

Additional file 3. Device reported leak data.

Additional file 4. Populations of patients depending on transformed manufacturer expressions of leaks.

Additional file 5. Mask characteristics $(n=1484)$.

Additional file 6. Explicative variables used during univariate analyses.

Additional file 7. Statistical analyses.

Additional file 8. Distribution frequency of the Epworth Sleepiness Scale (ESS) scores. The dashed line corresponds to cumulative frequency.

Additional file 9. Brand, series and mode of device used by patients.

Additional file 10. Univariate linear regression with patient-reported leak (0-10 VAS score) as the variable-of-interest.

Additional file 11. Multivariable linear regressions with patient-reported leak as the variable-of-interest (0-10 VAS score), summary of significant explanatory-variables.

Additional file 12. Association of mask related side-effects.

Additional file 13. Visual Analogue Scales for mask related side-effect scores (0-10 score) according to the presence/absence of a bed partner.

Additional file 14. Mask related side-effects categorized by previous (before 2013) or recent masks (since 2013) and subgroups of masks (nasal, oronasal and nasal pillows).

Additional file 15. Summary of the three most recent and largest cohort studies (>500 patients) reporting mask related side-effects in CPAP-treated patients.

\section{Abbreviations}

AHI: Apnea-Hypopnea-Index; CPAP: Continuous positive airway pressure; ESS: Epworth Sleepiness Scale; MRSEs: Mask related side-effects; NM: Nasal mask; NPM: Nasal pillow mask; ONM: Oronasal mask; PCA: Principal component analysis.

\section{Acknowledgements}

The authors would like to thank Doctor Sandrine Pontier-Marchandise (USI et Service de Pneumologie, Hôpital Larrey, 31059 TOULOUSE) for her review of the present manuscript.

The authors would like to thank the Apard team for their help in carrying out this study (administrative Team: Pierre Coulot, Bernard Alsina, Valérie Bachelier, Christophe Jeanjean, Philippe Lansard, Joël Nogue, Magali Partyka; technician team: Matthieu Alberti, Julien Bauchu, Yannick Baudelot, Gregory Bel, Julien Bernard, Julien Bourrel, Frédéric Bousquet, David Crespy, Olivier Cubero, Eric Deghal, Fabien Deville, Sébastien Faure, Laure Ferraz, Olivier Gaubert, Georges Guichard, Franck Issert, Renaud Lopez, Mounia Maachou, Clément Maurin, David Minguez, Fabien Moubeche, Christophe Pinotti, Liva Ranaivo, Lazhar Saighi, Frédéric Sola, Frédéric Tallavignes, Olivier Tramier, JeanMichel Tribe, Jean-Marc Uriol, Romain Vernet).

\section{Authors' contributions}

DJ accessed all data and takes responsibility for the integrity and accuracy of the analysis. All authors contributed to and approved the final submitted manuscript. MCR, NM, DJ: study design, data collection, analysis, and manuscript preparation; JPM: study design and manuscript preparation; CMS: study design, data interpretation and manuscript preparation; CM: study design, 
data collection; JCB, CR: manuscript preparation; FB: data analysis; AB: study design, analysis and manuscript preparation. All authors read and approved the final manuscript.

\section{Availability of data and materials}

The datasets used and/or analyzed during the current study are available from the corresponding author on reasonable request.

\section{Ethics approval and consent to participate}

InterfaceVent is registered with ClinicalTrials.gov (NCT03013283. The protocol complied with the Declaration of Helsinki and was reviewed and approved by an independent ethics committee (Comité de Protection des Personnes Sud Mediterranée 1; reference number RO-2016/50).

\section{Consent for publication}

Not applicable.

\section{Competing interests}

Dr Carey Suehs reports one grant from AstraZeneca, outside the submitted work.Dr. Jean Christian Borel reports grants from Philips, during the conduct of the study; grants and personal fees from Philips, salaries from AGIR à dom, personal fees and other from RESMED, other from NOMICS, outside the submitted work.Dr Claudio Rabec has performed lecturing at sponsored meetings and/or participated in boards for the following companies in the last 5 years: Resmed, Philips, Lowenstein, Air Liquide Medical Systems.Pr. Arnaud Bourdin reports grants, personal fees, non-financial support and other from AstraZeneca, grants, personal fees, non-financial support and other from Boeringher Ingelheim, grants, personal fees, non-financial support and other from GlaxoSmithKline, personal fees, non-financial support and other from Novartis, personal fees and non-financial support from Teva, personal fees, non-financial support and other from Regeneron, personal fees, non-financial support and other from Chiesi Farmaceuticals, grants, personal fees, non-financial support and other from Actelion, personal fees from Gilead, non-financial support and other from Roche, other from Nuvaira, from null, outside the submitted work.Dr Dany Jaffuel has performed lecturing at sponsored meetings for the following companies in the last 5 years: Apard, Bastide, Loewenstein Medical, Philips, SEFAM. He has sat on advisory boards for the following companies in the last 5 years: Lowenstein Medical, SEFAM. He has received sponsorship support to attend academic meetings in the last 5 years from Lowenstein Medical, Resmed, Philips and SEFAM.MCR, JPM, CM, FB, NM, report no conflicts of interest in relation to the present work.

\section{Author details \\ ${ }^{1}$ IMAG, CNRS, Montpellier University, Montpellier University Hospital, Mont- pellier, France. ${ }^{2}$ Apard Groupe Adène, Montpellier, France. ${ }^{3}$ Department of Respiratory Diseases, Montpellier University Hospital, Arnaud de Villeneuve Hospital, CHRU Montpellier, 371, Avenue Doyen Giraud, 34295 Montpellier Cedex 5, France. ${ }^{4}$ Department of Medical Information, Montpellier University Hospital, Montpellier, France. ${ }^{5}$ Inserm U1042, HP2 (Hypoxia PhysioPathology) LaboratoryCentre Hospitalier Universitaire Grenoble Alpes, Grenoble Alps University, Grenoble, France. ${ }^{6}$ Pulmonary Department and Respiratory Critical Care Unit, University Hospital Dijon, Dijon, France. ${ }^{7}$ PhyMedExp (INSERM U 1046, CNRS UMR9214), Montpellier University, Montpellier, France. ${ }^{8}$ Pulmo- nary Disorders and Respiratory Sleep Disorders Unit, Polyclinic Saint-Privat, Boujan sur Libron, France.}

Received: 17 November 2020 Accepted: 6 January 2021

Published online: 15 January 2021

\section{References}

1. Benjafield AV, Ayas NT, Eastwood PR, Heinzer R, Ip MSM, Morrell MJ, et al. Estimation of the global prevalence and burden of obstructive sleep apnoea: a literature-based analysis. Lancet Respir Med. 2019;7:687-98.

2. Heinzer R, Marti-Soler H, Haba-Rubio J. Prevalence of sleep apnoea syndrome in the middle to old age general population. Lancet Respir Med. 2016;4:e5-6.
3. Epstein LJ, Kristo D, Strollo PJ, Friedman N, Malhotra A, Patil SP, et al. Clinical guideline for the evaluation, management and long-term care of obstructive sleep apnea in adults. J Clin Sleep Med. 2009;5:263-76.

4. Patil SP, Ayappa IA, Caples SM, Kimoff RJ, Patel SR, Harrod CG. Treatment of adult obstructive sleep apnea with positive airway pressure: an American academy of sleep medicine systematic review, meta-analysis, and GRADE assessment. J Clin Sleep Med. 2019;15:301-34.

5. Yu J, Zhou Z, McEvoy RD, Anderson CS, Rodgers A, Perkovic V, et al. Association of positive airway pressure with cardiovascular events and death in adults with sleep apnea: a systematic review and meta-analysis. JAMA. 2017;318:156-66.

6. Weaver TE, Maislin G, Dinges DF, Bloxham T, George CFP, Greenberg H, et al. Relationship between hours of CPAP use and achieving normal levels of sleepiness and daily functioning. Sleep. 2007;30:711-9.

7. Bouloukaki I, Giannadaki K, Mermigkis C, Tzanakis N, Mauroudi E, Moniaki $\mathrm{V}$, et al. Intensive versus standard follow-up to improve continuous positive airway pressure compliance. Eur Respir J. 2014;44:1262-74.

8. Chai-Coetzer CL, Luo Y-M, Antic NA, Zhang X-L, Chen B-Y, He Q-Y, et al. Predictors of long-term adherence to continuous positive airway pressure therapy in patients with obstructive sleep apnea and cardiovascular disease in the SAVE study. Sleep. 2013;36:1929-37.

9. Engleman HM, Wild MR. Improving CPAP use by patients with the sleep apnoea/hypopnoea syndrome (SAHS). Sleep Med Rev. 2003;7:81-99.

10. Shapiro GK, Shapiro CM. Factors that influence CPAP adherence: an overview. Sleep Breath. 2010;14:323-35.

11. Sawyer AM, Gooneratne NS, Marcus CL, Ofer D, Richards KC, Weaver TE. A systematic review of CPAP adherence across age groups: clinical and empiric insights for developing CPAP adherence interventions. Sleep Med Rev. 2011;15:343-56.

12. Pépin $J$, Leger $P$, Veale $D$, Langevin B, Robert D, Lévy P. Side effects of nasal continuous positive airway pressure in sleep apnea syndrome. Study of 193 patients in two French sleep centers. Chest. 1995;107:375-81.

13. Borel JC, Tamisier R, Dias-Domingos S, Sapene M, Martin F, Stach B, et al. Type of mask may impact on continuous positive airway pressure adherence in apneic patients. PLoS ONE. 2013;8:e64382.

14. Van Ryswyk E, Anderson CS, Antic NA, Barbe F, Bittencourt L, Freed R, et al. Predictors of long-term adherence to continuous positive airway pressure in patients with obstructive sleep apnea and cardiovascular disease. Sleep. 2019;42:zsz152.

15. Baratta F, Pastori D, Bucci T, Fabiani M, Fabiani V, Brunori M, et al. Long-term prediction of adherence to continuous positive air pressure therapy for the treatment of moderate/severe obstructive sleep apnea syndrome. Sleep Med. 2018;43:66-70.

16. Luyster FS, Strollo PJ, Thunström E, Peker Y. Long-term use of continuous positive airway pressure therapy in coronary artery disease patients with nonsleepy obstructive sleep apnea. Clin Cardiol. 2017;40:1297-302.

17. Campos-Rodriguez F, Martinez-Alonso M, Sanchez-de-la-Torre M, Barbe F, Spanish Sleep Network. Long-term adherence to continuous positive airway pressure therapy in non-sleepy sleep apnea patients. Sleep Med. 2016;17:1-6.

18. Bachour A, Vitikainen P, Virkkula P, Maasilta P. CPAP interface: satisfaction and side effects. Sleep Breath. 2013;17:667-72.

19. Hotelling $H$. Analysis of a complex of statistical variables into principal components. J Educ Psychol. 1933;24:417-41.

20. Kemsley EK. Discriminant analysis of high-dimensional data: a comparison of principal components analysis and partial least squares data reduction methods. Chemomet Intell Lab Syst. 1996;33:47-61.

21. Nino-Murcia G, McCann CC, Bliwise DL, Guilleminault C, Dement WC. Compliance and side effects in sleep apnea patients treated with nasal continuous positive airway pressure. West J Med. 1989;150:165-9.

22. Gay P, Weaver T, Loube D, Iber C, Positive Airway Pressure Task Force, Standards of Practice Committee, et al. Evaluation of positive airway pressure treatment for sleep related breathing disorders in adults. Sleep. 2006;29:381-401.

23. Bachour A, Vitikainen P, Maasilta P. Rates of initial acceptance of PAP masks and outcomes of mask switching. Sleep Breath. 2016;20:733-8.

24. Cistulli PA, Sullivan CE. In search of a good fit: CPAP therapy mask selection for obstructive sleep apnoea. Respirology. 2019;24:199-200. 
25. Andrade RGS, Viana FM, Nascimento JA, Drager LF, Moffa A, Brunoni AR, et al. Nasal vs oronasal CPAP for OSA treatment: a meta-analysis. Chest. 2018;153:665-74.

26. Baltzan MA, Elkholi O, Wolkove N. Evidence of interrelated side effects with reduced compliance in patients treated with nasal continuous positive airway pressure. Sleep Med. 2009;10:198-205.

27. Meslier N, Lebrun T, Grillier-Lanoir V, Rolland N, Henderick C, Sailly JC, et al. A French survey of 3,225 patients treated with CPAP for obstructive sleep apnoea: benefits, tolerance, compliance and quality of life. Eur Respir J. 1998;12:185-92

28. Goh KJ, Soh RY, Leow LC, Toh ST, Song PR, Hao Y, et al. Choosing the right mask for your Asian patient with sleep apnoea: A randomized, crossover trial of CPAP interfaces. Respirology. 2019;24:278-85.

29. Rowland S, Aiyappan V, Hennessy C, Catcheside P, Chai-Coezter CL, McEvoy RD, et al. Comparing the efficacy, mask leak, patient adherence, and patient preference of three different CPAP interfaces to treat moderatesevere obstructive sleep apnea. J Clin Sleep Med. 2018;14:101-8.

30. Société de Pneumologie de Langue Française, Société Française d'Anesthésie Réanimation, Société Française de Cardiologie, Société Française de Médecine du Travail, Société Française d'ORL, Société de Physiologie, et al. Recommendations for clinical practice. Obstructive sleep apnea hypopnea syndrome in adults. Rev Mal Respir. 2010;27:806-33.
31. Kohler M, Smith D, Tippett V, Stradling JR. Predictors of long-term compliance with continuous positive airway pressure. Thorax. 2010;65:829-32.

32. Valentin A, Subramanian S, Quan SF, Berry RB, Parthasarathy S. Air leak is associated with poor adherence to autoPAP therapy. Sleep. 2011;34:801-6.

33. Rotty M-C, Mallet J-P, Suehs CM, Martinez C, Borel J-C, Rabec C, et al. Is the 2013 American Thoracic Society CPAP-tracking system algorithm useful for managing non-adherence in long-term CPAP-treated patients? Respir Res. 2019;20:209.

34. Farré R, Navajas D, Gozal D, Montserrat JM. Telematic multi-physician decision-making for improving CPAP prescription in sleep apnoea. Arch Bronconeumol. 2019;55:604-6.

35. Garmendia O, Suarez-Giron MC, Torres M, Montserrat JM. Telemedicine in sleep apnea: a simple approach for nasal pressure (CPAP) treatment. Arch Bronconeumol. 2018;54:491-2.

\section{Publisher's Note}

Springer Nature remains neutral with regard to jurisdictional claims in published maps and institutional affiliations.
Ready to submit your research? Choose BMC and benefit from:

- fast, convenient online submission

- thorough peer review by experienced researchers in your field

- rapid publication on acceptance

- support for research data, including large and complex data types

- gold Open Access which fosters wider collaboration and increased citations

- maximum visibility for your research: over 100M website views per year

At BMC, research is always in progress.

Learn more biomedcentral.com/submissions 